\title{
Joalet Steenkamp Takes the Heat for Furnace Photography
}

\author{
Lynne Robinson
}

\section{meet a member}

This regular feature highlights a TMS member and his or her activities both within and outside of the realm of minerals, metals, and materials science and engineering. To suggest a candidate for a Meet a Member article, contact Lynne Robinson, Magazine Editor, JOM, at Irobinson@tms.org.

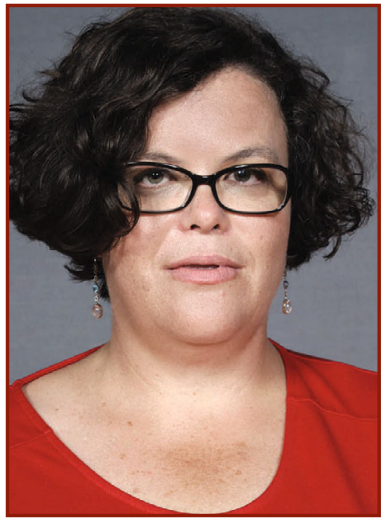

Joalet Steenkamp
Pyrometallurgy is Joalet Steenkamp's professional passion and resolving furnace tapping issues is her responsibility as chief engineer of MINTEK's Pyrometallurgy Division in Johannesburg, South Africa. But, it is her eye for beauty that draws her close to the furnace mouth to capture the drama of molten material. . alive, dangerous, and visually stunning. . .with her photography lens.

Steenkamp first became interested in photography at about 10 years of age, when she received a simple automatic film camera as a gift from her parents. She graduated to more sophisticated equipment over the years, but points to a series of photography classes that she took in 2005 as the key milestone in developing her technique. "The lecturers were active

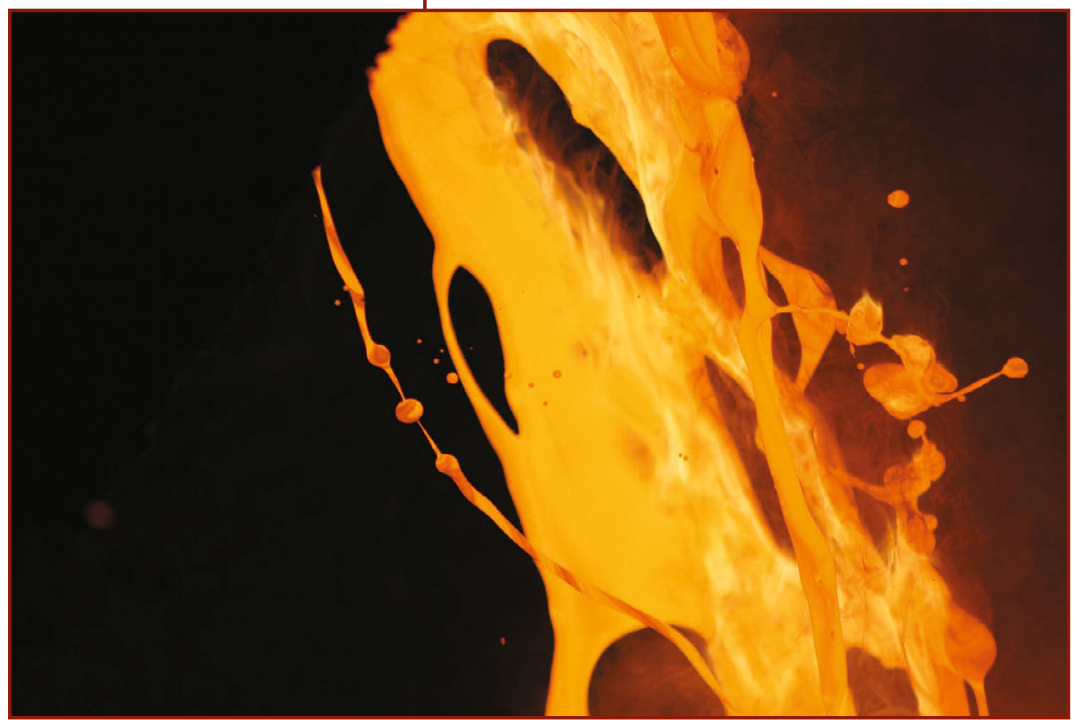

Sphere: Liquid silicomanganese alloy and slag tapped from a sub-merged arc furnace at Transalloys, South Africa, March 14, 2013 (C) Joalet Steenkamp. This image is now on permanent display at TMS headquarters. photographers themselves and experts in their respective fields," she said. "It was during this time that I went from using my camera in point-and-shoot mode, to operating it in manual mode, which allows for much more artistic freedom. The need to select your subject matter with care, focusing on details, was emphasized throughout the course."

While Steenkamp noted that one of the courses touched on industrial photography, she primarily focused on taking pictures of the natural world during this time. Then, a few years later as a Ph.D. student, she

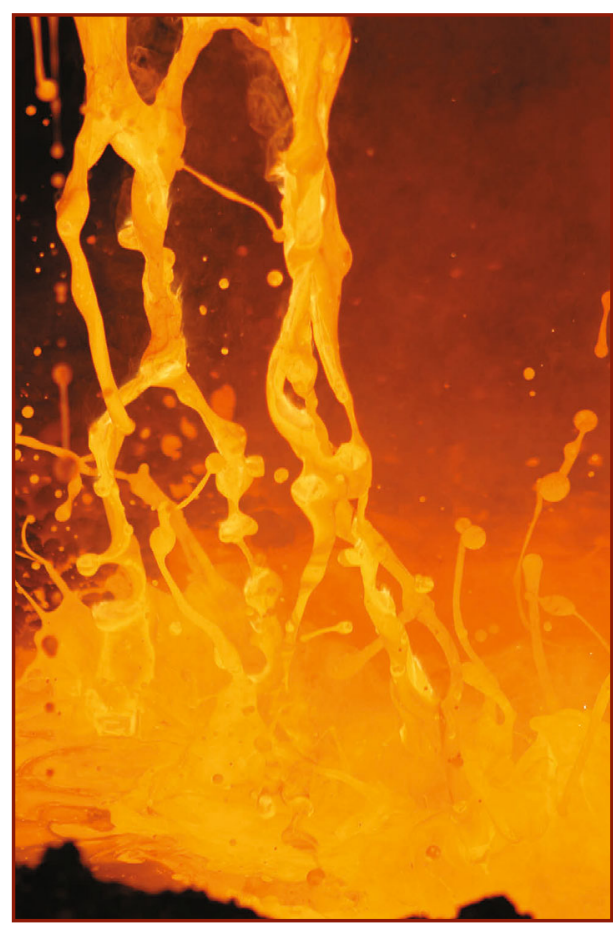

Dance: Liquid silicomanganese alloy and slag flowing into the ladle at Transalloys, South Africa, March 14th, 2013 @ Joalet Steenkamp. 
was offered the opportunity to photograph furnace processes at Transalloys in South Africa, and a whole new world of artistic possibilities opened to her.

Today, Steenkamp specializes in close-up images of pyrometallurgical operations, putting her in adventurous proximity of furnaces with tapping temperatures of $1600-1650^{\circ} \mathrm{C}$. Apart from the extreme heat, the smelter environment is dusty, noisy, and replete with mobile equipment moving on the ground and overhead. "These are fairly dangerous situations and my response time has to be fast, both in taking photographs and in getting out of the way of operations," she commented. Having worked as a process engineer on industrial (steelmaking and ilmenite smelting) and pilot-scale (ilmenite smelting and high carbon ferromanganese production) operations, Steenkamp has developed a keen intuition of the risks surrounding her in that environment. "Yet, I prefer to have someone with me to focus on the safety matters, while I focus on taking photographs," she said.

Steenkamp's equipment of choice is her Canon EOS 30D digital SLR and Canon EF 70-300mm f/4-5.6 lens. "I install the camera on a tripod and release the shutter using a shutter release cable. On the camera itself, I work with an ISO-speed of 100 and manually adjust the exposure using the readings from the built-in light meter," she explained. "My secret in obtaining the richness in colors is the polarizing filter I attach to the lens."

The reward for all these efforts comes when Steenkamp downloads her photographs, opens them for the first time, and "finds that one gem to which my heart-response is 'yes'." Most times, however, that discovery does not happen right away. "I often have to go back to a set of photographs a number of weeks or even months later, to really appreciate them," she said.

Steenkamp's furnace photographs have caught the attention of the professional community, both for their technical interest and almost hypnotic beauty. In fact, one of her images, Sphere, is on permanent display in the new TMS headquarters building - Steenkamp notes that this is her proudest photographic accomplishment to date.

As to the future, Steenkamp dreams of taking photographs, especially of tapping operations, in all 18 commodities produced by pyrometallurgical means in South Africa, on as many sites as possible. Eventually, she hopes to publish a print volume combining her photographs with favorite poems exploring fire-and-light themes.

"Photography allows me to capture the beauty that I see in ways that I am unable to do otherwise," she said. "In the case of the 'hot stuff', photography allows me to express my love of pyrometallurgy."

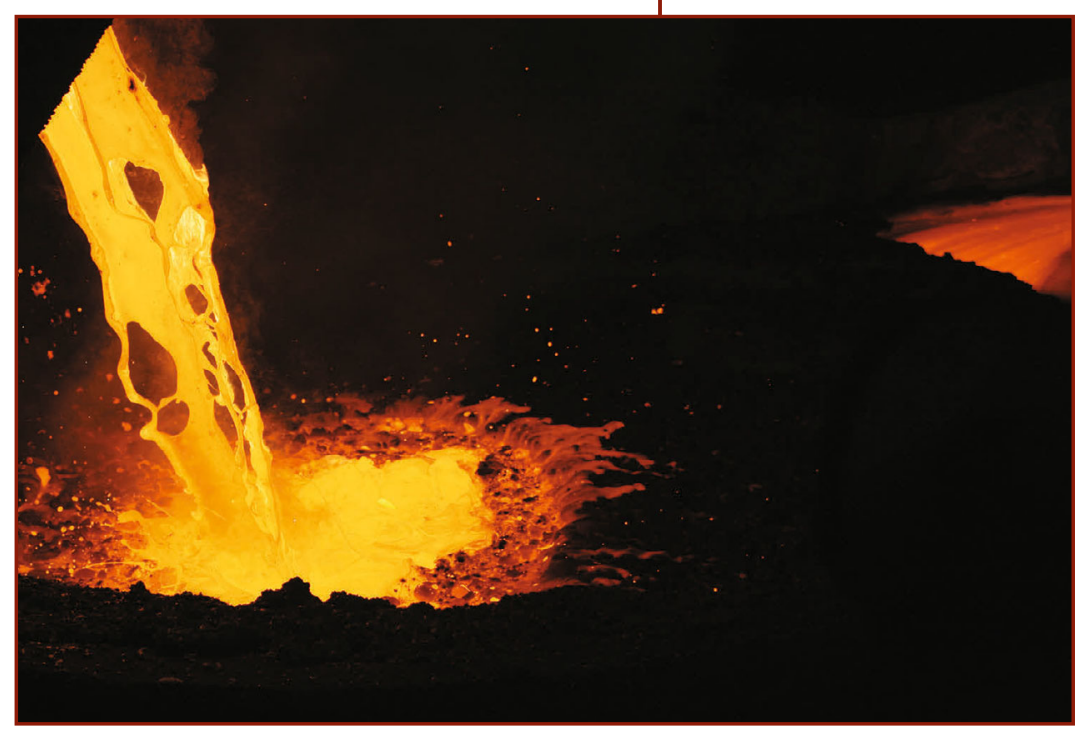

Follow Me: Liquid silicomanganese alloy and slag flowing from the tap launder into the metal ladle, and then slag into the slag pot, Transalloys, South Africa, March 14, 2013 @ Joalet Steenkamp.

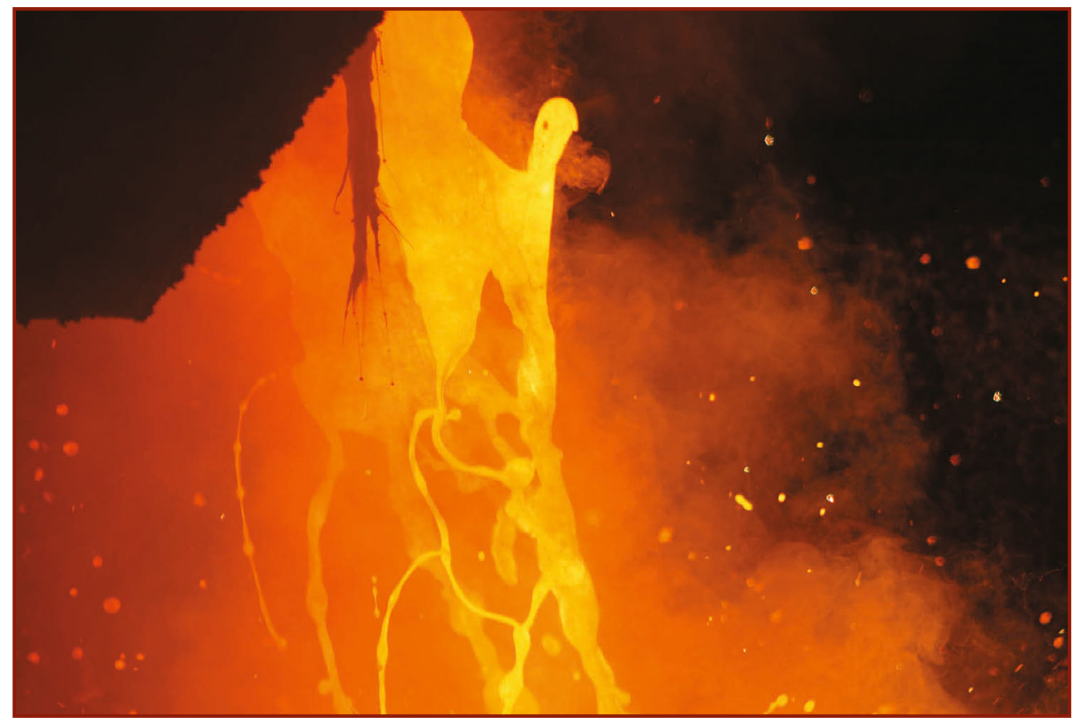

Beard on Fire: Liquid silicomanganese alloy and slag flowing from the tap launder to the ladle at Transalloys, South Africa, March 14th, 2013 @ Joalet Steenkamp. 